\title{
Length of training, hostility and the martial arts: a comparison with other sporting groups
}

\author{
Kevin Daniels BSc, PhD and Everard Thornton* BSc, PhD \\ School of Management, Cranfield Institute of Technology, Bedfordshire, UK; *Department of Psychology, \\ University of Liverpool, Merseyside, UK
}

\begin{abstract}
Previous research has indicated that training in the martial arts leads to a reduction in levels of hostility. However, such research has only compared hostility within martial arts groups. The present research compares two martial arts groups and two other sporting groups on levels of assaultive, verbal and indirect hostility. Moderated multiple regression analyses revealed a significant interaction between length of training in the respondent's stated sport and whether that sport was a martial art in predicting assaultive and verbal hostility. The form of the interaction suggests that participation in the martial arts is associated, over time, with decreased feelings of assaultive and verbal hostility.
\end{abstract}

Keywords: Hostility, martial arts, length of training

The martial arts (e.g. karate) are forms of self-defence which originated in the Far East. Practitioners of such defence forms often make claims regarding the utility of the martial arts in heightening the psychological well-being of the individual. Indeed, a recent review of the few studies conducted suggests that martial arts training is generally conducive to psychological well-being ${ }^{1}$.

Perhaps the most controversial aspect of the martial arts, however, is that increased involvement in the martial arts appears to be associated with a decrease in hostility ${ }^{2-5}$. Although this would appear to conform with claims made by martial arts practitioners, it is contrary to Bandura's social learning model of hostility ${ }^{6}$ which predicts that exposure to hostile acts serves to increase hostility.

Therefore Bandura's model may indicate that five aspects of martial arts training could serve to increase hostility. These are the provision of a hostile repertoire; disinhibition of hostile actions; change in the ordering of responses to arousal with hostility becoming prepotent; symbolic rehearsal may act to increase hostile fantasy; and combat experience may enhance both fighting skills and viciousness. Given this perspective, it may be expected that training in the martial arts would actually serve to increase overall levels of hostility.

Address for correspondence: Dr K. Daniels

(C) 1992 Butterworth-Heinemann Ltd 0306-3674/92/030118-03
The empirical research just cited in support of a negative correlation of hostility with increased martial arts training examined only differences between martial arts practitioners at different levels of ability, and it is possible that any form of physical exercise may be associated with decreased hostility, a question which this paper addresses.

\section{Subjects and methods}

Subjects were male undergraduate students who participated in either campus karate or ju-jitsu clubs (the martial arts group, $n=40$ ) or were members of campus badminton or rugby clubs $(n=39)$. The selection of male undergraduates as subjects meant that the samples were homogeneous with regard to age, sex, education and (to a lesser extent) socioeconomic status.

Nosanchuk and MacNeil ${ }^{4}$ suggest that the hostility-reducing effects of the martial arts are found only in the traditional martial arts. The two groups of martial arts classes studied here conformed to three of Nosanchuk's criteria for a 'traditional' martial $\mathrm{art}^{3,4}$. That is, emphasis was placed upon opponentless rehearsal of moves (the kata), there was negative sanctioning of heavy contact during sparring and respect was accorded to the instructor (sensei), the uniform (gi), the class (dojo) and fellow students. Nosanchuk's fourth condition, the importance of meditation and philosophy, was not met in regard to the use of meditation.

Mean age(s.d.) was 21.2(2.7) years and subjects had been training in their respective sport for a mean (s.d.) of 4.7(4.6) years.

\section{Questionnaire}

The questionnaire consisted of the assaultive, verbal and indirect hostility scales of the Buss-Durkee Hostility Inventory ${ }^{7}$. Assaultive (e.g. hitting someone), verbal (e.g. raising one's voice in an argument) and indirect (e.g. smashing objects) hostility scales were chosen, since they relate to overtly hostile behaviour. Respondents were asked to rate the likelihood, on a 5-point scale, that they would carry out a number of such types of behaviour.

An anonymous self-response format was used, and participation in the study was voluntary. Questionnaires were given to club instructors/captains to 
distribute to members of their groups to complete in their own time. The actual response rate was not directly ascertained, but reported by the distributors to be at least $90 \%$.

\section{Results}

Tables 1 and 2 show the correlations between the dimensions of hostility measured and length of training, together with group means and standard deviations.

Moderated multiple regression analyses were used to test the interactive effects of length of training with whether one participates in a martial art or not (the latter being a dummy variable, coded as 1 for the martial arts group and 0 for the other sportsmen). Multiple regression can easily accommodate interaction terms which are analogous to those tested in

Table 1. Length of training, assaultive, verbal and indirect hostility

\begin{tabular}{lrr}
\hline Group & Martial arts & Other sports \\
\hline Length of training & $1.6(1.7)$ & $8.1(4.4)$ \\
Assaultive hostility & $21.5(5.4)$ & $21.0(6.0)$ \\
Verbal hostility & $28.8(6.2)$ & $30.0(5.0)$ \\
Indirect hostility & $14.8(4.9)$ & $15.4(4.2)$ \\
\hline
\end{tabular}

Values are mean(s.d.)

Table 2. Correlations* between length of training, assaultive, verbal and indirect hostility

\begin{tabular}{lccc}
\hline Attribute & $\begin{array}{c}\text { Length of } \\
\text { training }\end{array}$ & $\begin{array}{c}\text { Assaultive } \\
\text { hostility }\end{array}$ & $\begin{array}{c}\text { Verbal } \\
\text { hostility }\end{array}$ \\
\hline $\begin{array}{l}\text { Length of training } \\
\text { Assaultive hostility }\end{array}$ & 0.06 & & \\
Verbal hostility & 0.14 & 0.53 & \\
Indirect hostility & 0.12 & 0.25 & 0.37 \\
\hline * Correlations $>0.30$ are significant at $P<0.01$; correlations $>0.20$ \\
are significant at $P<0.05$
\end{tabular}

Table 3. Moderated multiple regressions of length of training and participation in the martial arts on hostility variables

\begin{tabular}{llrr}
\hline Dependent variable & \multicolumn{1}{c}{ Step } & $\beta$ & $\Delta R^{2}$ \\
\hline Assaultive hostility & 1 Length of training & 0.19 & 0.021 \\
& Martial arts participation & 0.19 & \\
& 2 & & $0.183^{*}$ \\
& Interaction & -0.56 & \\
Verbal hostility & 1 & & 0.021 \\
& Length of training & 0.11 & \\
& Martial arts participation & -0.05 & \\
& 2 & & $0.059+$ \\
Indirect hostility & 1 & -0.32 & \\
& Lenteraction & & 0.016 \\
& Martial arts participation & 0.17 & \\
& 2 & 0.07 & 0.004 \\
& Interaction & -0.08 & \\
\hline
\end{tabular}

${ }^{*} P<0.01 ;+P<0.05$ the analysis of variance ${ }^{8}$. Cohen and Cohen ${ }^{8}$ indicate that the correct form to evaluate an interaction within multiple regression is to use a hierarchical analysis, where the simple linear effects (length of training and martial arts/sports participation) are entered at the first step (1) and the interaction is entered at the second step (2) (represented by the product of the simple linear effects). Three such analyses were conducted - one for each of the hostility scales used and these are shown in Table 3.

As can be seen from Table 3, there is significant interaction between length of training and participation in the martial arts on assaultive and verbal, but not on indirect, hostility. The significant interactions indicate that length of training in the martial arts is negatively related to assaultive hostility (the interaction accounts for just over $18 \%$ of the variance) and verbal hostility (the interaction accounts for nearly $6 \%$ of the variance). No simple linear effects reached significance, indicating that martial arts training, by itself, is not associated with low levels of hostility and that length of training in physical exercise (martial arts or otherwise) is not associated with a decrease in hostility.

\section{Discussion}

The moderated regression analyses indicated that increased training in the martial arts is associated with low scores on the assaultive and verbal hostility scales of the Buss-Durkee Hostility Inventory. Moreover, the lack of significant linear effects for length of training indicates that this effect may be peculiar to the martial arts. Also, since no significant linear effect was found for the dummy variable (participation in the martial arts), the association between martial arts and low levels of hostility increases in strength with the number of years spent practising the martial arts, which supports previous research $^{2-5}$. Moreover, stronger effects may be found for martial arts groups with longer mean lengths of training than the group reported here (who had been training for a mean of only 1.6 years, see Table 1).

In addition, assaultive and verbal hostility were highly correlated (see Table 2). Therefore, it may be that the significant interaction of martial arts participation and length of training in predicting verbal hostility is mediated by effects on assaultive hostility. Increased martial arts training may serve to decrease assaultive hostility. In turn, decreases in assaultive hostility may generalize into decreases in other forms of hostility. This conclusion is supported for the stronger association of the assaultive interaction than verbal hostility. However, cross-sectional data cannot fully address this suggestion.

Four possible causal mechanisms exist which may lead to an association between low levels of hostility and increased martial arts participation. First, the negative sanctioning of hostile behaviour that occurs in the martial arts may serve to lessen assaultive and verbal hostility, despite factors that may be expected to increase hostility through rehearsal.

It is also possible that the more hostile practitioners are selected out over a period of time (by peer or instructor pressure, or through a realization that the 
martial arts are not for them), leaving a group with low hostility. This hypothesis was tested in a retrospective study ${ }^{4}$, and gained little support.

The results may be due to the use of self-report instruments, with expert martial arts practitioners being keen to present a socially desirable image. However, the use of an anonymous self-completion format discourages respondents from faking?.

Finally, it is possible that the results are due to transitory decreases in hostility brought about by the short-term effects of training, which disappear in a matter of hours. Evidence for this view comes from research which demonstrates that exercise leads to short-term decreases in state anxiety but not longterm decreases in trait anxiety ${ }^{10-12}$. Hostility may decrease after exercise, since exercise leads to short-term decreases in arousal ${ }^{13}$. However, the Buss-Durkee Hostility Inventory asks the respondent to rate usual behaviour, rather than present mood and therefore the results are possibly more enduring than suggested by a transitory mood hypothesis.

The issues raised above clearly need to be investigated before courses in the martial arts can be recommended as a means of increasing ability to defend oneself without increasing one's disposition to harm people. In particular, a longitudinal study of beginners in the martial arts needs to be undertaken $^{4,5}$, that examines both the short-term transitory 'state' effects and longer term 'trait' effects.

\section{References}

1 Fuller JR. Martial arts and psychological health. Br J Med Psychol 1988; 61: 317-28.

2 Rothpearl A. Personality traits in martial artists: a descriptive approach. Percep Motor Skills 1980; 50: 395-401.

3 Nosanchuk TA. The way of the warrior: the effects of traditional martial arts training on aggressiveness. Hum Rel 1981; 34: 435-44.

4 Nosanchuk TA, MacNeil MLC. Examination of the effects of traditional and modern martial arts training on aggressiveness. Aggr Behav 1989; 15: 153-9.

5 Daniels K, Thornton EW. An analysis of the relationship between training and hostility in the martial arts. J Sports Sci 1990; 8: 95-101.

6 Bandura A. Social learning theory of aggression. In: Knutson JF, ed. The Control of Aggression. New York, USA: Aldine, 1973.

7 Buss AH, Durkee A. An inventory for assessing different kinds of hostility. J Consult Psychol 1957; 21: 343-9.

8 Cohen J, Cohen P. Applied Multiple Regression/Correlation Analysis for the Behavioural Sciences. 2nd ed. Englewood Cliffs, New Jersey, USA: Erlbaum, 1983.

9 Oppenheim AN. Questionnaire Design and Attitude Measurement. London, UK: Heinemann, 1966.

10 Berger BC, Owen DR. Stress reduction and mood enhancement in four exercise modes: swimming, body conditioning, hatha yoga, and fencing. Res $Q$ Exerc Sport 1988; 59: 148-59.

11 Plante TG, Rodin J. Physical fitness and enhanced psychological health. Curr Psychol Res Rev 1990; 9: 3-24.

12 Steptoe A, Moses J, Mathews A, Edwards S. Aerobic fitness psychophysiological reactions to mental tasks. Psychophysiology 1990; 27: 264-74.

13 Zillman D. Transfer of excitation in emotional behaviour. In: Cacioppo JT, Petty RE eds. Social Psychophysiology. New York, USA: Guilford, 1983.
Single motif

BASM blazer badge

Ladies head scarves

BASM sweatshirts

BASM T-shirts

New stock to order will include:

umbrella (£20); sweater (£27); sweatshirts and polo shirts and white short-sleeved dress shirts,

BASM motif $(£ 17)$

All enquiries and orders (with cash!) to National Sales Officer: Mr John Clegg, Birch Lea, 67 Springfield Lane, Eccleston, St. Helens, Merseyside WA10 5HB, UK. Tel: (0744) 28198
Multi-motif

$$
\begin{aligned}
& £ 6+£ 1 \mathrm{p} / \mathrm{p} \\
& £ 6+£ 1 \mathrm{p} / \mathrm{p} \\
& £ 5+£ 1 \mathrm{p} / \mathrm{p} \\
& £ 5+£ 1 \mathrm{p} / \mathrm{p} \\
& £ 11+£ 1 \mathrm{p} / \mathrm{p} \\
& £ 10+£ 1 \mathrm{p} / \mathrm{p} \\
& £ 6+£ 1 \mathrm{p} / \mathrm{p}
\end{aligned}
$$

Light blue, BASM logo; M, 38"; L, 40"; XL, 44"

Navy blue, BASM logo; S, 36"; M, 38"; XL, 44" 